\title{
Synthesis of pseudoboehmite - effect of acetate ion
}

\author{
Matheus Francelino Bezerra da Silva ${ }^{a}$, Caroline Valadão Pacheco ${ }^{a}$, Renato Meneghetti Peres ${ }^{a}$,
}

Leila Figueiredo de Miranda ${ }^{a}$, Nelson Batista de Lima ${ }^{b}$, Rene Ramos de Oliveira ${ }^{b}$, Ayrton Bernussi ${ }^{c}$, Antônio Hortencio Munhoz Junior ${ }^{a} *$ (D)

${ }^{a}$ Universidade Presbiteriana Mackenzie, Escola de Engenharia, Rua da Consolação, 930, Consolação, 01302-907, São Paulo, SP, Brasil

${ }^{b}$ Instituto de Pesquisas Energéticas e Nucleares - IPEN, São Paulo, SP, Brasil

${ }^{c}$ Texas Tech University, Department of Electrical and Computer Engineering, 79409, Lubbock, TX, USA

Received: October 22, 2019; Revised: December 11, 2019; Accepted: January 16, 2020

Pseudoboehmite $\left(\mathrm{AlOOH} \cdot \mathrm{xH}_{2} \mathrm{O}\right)$ is one of the precursors of alumina. Its calcination produces different phases of alumina and at $1200^{\circ} \mathrm{C}$ the most stable phase, $\alpha$-alumina, is formed. The synthesis of pseudoboehmite by the sol-gel process results in a product with high purity, high specific surface area, and high reproducibility. The aging of the pseudoboehmite at temperatures above room temperature results in pseudoboehmites with distinct properties. In this work we report the synthesis of pseudoboehmite by the sol-gel process, using aluminum nitrate and aluminum chloride as precursors, and investigate the effect of acetate ion on crystallinity, adsorption capacity, particle morphology, thermal properties and specific surface area. The X-ray diffraction data of the synthesized pseudoboehmites in the presence of the acetate ion revealed high quality nanoparticles.

Keywords: Pseudoboehmite, acetate ion, powder synthesis, factorial experimental design, sol-gel.

\section{Introduction}

Pseudoboehmite $\left(\mathrm{AlOOH} . \mathrm{xH}_{2} \mathrm{O}\right)$ is an aluminum compound of the synthetic fine ceramic type, precursor of alumina. It has an orthorhombic structure $(\mathrm{a}=0.366936 \mathrm{~nm}, \mathrm{~b}=1.221 \mathrm{~nm}$, $\mathrm{c}=0.288679 \mathrm{~nm})$, in which it is formed by two octahedra layers of oxygens partially filled by aluminum cations ${ }^{1}$. Its unit cell is slightly larger than that of the boehmite and this occurs due to the large incorporation of water ${ }^{2}$.

Several papers in the literature report the importance of this material in catalysis ${ }^{3}$, drug delivery system ${ }^{4}$ including DOX, a typical chemotherapeutic anticancer $\operatorname{drug}^{5}$ and nanocomposites ${ }^{6,7}$. The presence of pseudoboehmite in the catalyst Pt/(HZSM-48+pseudoboehmite) for the synthesis of benzene through methylcyclopentane shows that pseudoboehmite increases the total amount of acid sites and weakens the acid strength, compared to those of the Pt/HZSM-48 catalyst. Lewis acid sites were more abundant than Brönsted acid sites over the Pt/(HZSM-48+pseudoboehmite) catalysts resulting in the increase of selectivity to the ring-enlargement reaction over to the ring-opening reaction ${ }^{3}$. It is difficult to overestimate the importance of alumina in today's catalysis. Therefore, from this point of view, undertaking research on the preparation of pseudoboehmite is most justified.

By its calcination $\alpha$-alumina is obtained, which is the most stable phase of alumina. The transformation of aluminum oxide to the more stable hexagonal form of alumina, $\alpha$-alumina, does not occur directly. Starting from the boehmite (ALOOH) or the pseudoboehmite, the transformation process goes

*e-mail: ahmunhoz@yahoo.com through a series of metastable phases, following the order presented in Equation $1^{8}$.

$\left(\right.$ AlOOH.xH $\left.{ }_{2} \mathrm{O}\right) \rightarrow \gamma-\mathrm{Al}_{2} \mathrm{O}_{3} \rightarrow \delta-\mathrm{Al}_{2} \mathrm{O}_{3} \rightarrow \theta-\mathrm{Al}_{2} \mathrm{O}_{3} \rightarrow \alpha-\mathrm{Al}_{2} \mathrm{O}_{3}$

The production of pseudoboehmite can be carried out by the sol-gel process using aluminum chloride or nitrate, for instance ${ }^{9}$. This process consists in the use of a suspension of fine particles of colloidal dimensions (sol) that under certain conditions transform into a continuous network (gel), thus generating a semi-rigid mass for later drying. The particle size and specific surface area of pseudoboehmite influences the temperature of transformation of pseudoboehmite in the transitional alumina and into $\alpha-\mathrm{Al}_{2} \mathrm{O}_{3}{ }^{9}$. Previous reports describe the use of acetate ion in the synthesis of pseudoboehmite ${ }^{10-13}$. It has been argued that the presence of the acetate ion in the alkaline reaction medium would be essential for obtaining thick plates morphology (near "2D" crystals) ${ }^{11}$. The synthesis of pseudoboehmite using aluminum nitrate and aluminum chloride as precursor using acetate in reaction synthesis has not been reported thus far. In this paper we study the influence of acetate ion in the synthesis of pseudoboehmite using aluminum nitrate, aluminum chloride, ammonium hydroxide, and sodium hydroxide.

Two-factor factorial experimental design is very useful in experimental procedures, in which the influence or interaction of variables on the expected outcome is desired. This procedure is performed, specifying the factor to be studied and assigning to it, +1 coefficients, for higher levels and -1, for lower levels. A two-level factorial design for the study of three variables is represented as $2^{3}$, resulting in 
eight tests arranged in a matrix of experiments. Thus, after a statistical calculation of the effects, it is possible to interpret the influences and / or interactions of the variables studied in the experimental process ${ }^{14,15}$.

\section{Experimental}

\subsection{Sample preparation}

The pseudoboehmite was obtained by precipitating a solution of aluminum salts in the presence of acetate ions in a basic solution, according to the upper and lower levels listed in Table 1. The precipitations were performed at room temperature, adopting after the synthesis, for all samples, the aging time of $96 \mathrm{~h}$, at the boiling temperature. For the synthesis of pseudoboehmites, 8 trials were obtained, organized in a factorial experimental design of $2^{3}$, in which the variables are the reagents themselves, classified as Aluminum Salt (A), Acetate (B) and hydroxide (C), all divided into $(+1)$ and lower levels $(-1)$, in order to analyze its effects on the properties of obtained product. Table 2 shows the matrix of experiments with the eight synthesis conditions. Note that the eight synthesis conditions are different.

The tests were carried out using the following molar ratio for the use of acetate: $1 \mathrm{~mol}$ of $\mathrm{Al}: 1 \mathrm{~mol}$ acetate $\left(\mathrm{CH}_{3} \mathrm{COONa}\right.$ or $\left.\mathrm{CH}_{3} \mathrm{COONH}_{4}\right): 50 \mathrm{~mol} \mathrm{H}_{2} \mathrm{O}$. Thus, a solution of nitrate or chloride salt $\left(\mathrm{AlCl}_{3} \cdot 6 \mathrm{H}_{2} \mathrm{O}\right.$ or $\left.\mathrm{Al}\left(\mathrm{NO}_{3}\right)_{3} \cdot 9 \mathrm{H}_{2} \mathrm{O}\right)$ and acetate $\left(\mathrm{CH}_{3} \mathrm{COONa}\right.$ or $\left.\mathrm{CH}_{3} \mathrm{COONH}_{4}\right)$ was dripped in an basic solution $\left(\mathrm{NaOH}\right.$ or $\left.\mathrm{NH}_{4} \mathrm{OH}\right)$ to give the pseudoboehmite gel.

In the factorial experimental design, the error can be estimated using the interactions of 3 orders. The error of the effects without the realization of repetitions can be estimated from the interactions of higher orders for $\mathrm{k} \geq 3$, which can be considered as non-significant. The equation that gives the variance of the effects can be estimated by Equation 2, where ef is the interaction effects considered as experimental errors, $\mathrm{V}(\mathrm{ef})$ is the variance and $l$ is the total number of effects considered, being also the number of degrees of freedom.

$$
\mathrm{V}(\mathrm{ef})=\sum(\mathrm{ef})^{2} / 1
$$

Table 1. Experimental variables and levels.

\begin{tabular}{lcc}
\hline \multicolumn{1}{c}{ Variables } & Lower level (-1) & Higher lever $(+1)$ \\
\hline A aluminum precursor & $\mathrm{AlCl}_{3} \cdot 6 \mathrm{H}_{2} \mathrm{O}$ & $\mathrm{Al}\left(\mathrm{NO}_{3}\right)_{3} \cdot 9 \mathrm{H}_{2} \mathrm{O}$ \\
\hline B acetate addition & $\mathrm{CH}_{3} \mathrm{COONa}$ & $\mathrm{CH}_{3} \mathrm{COONH}_{4}$ \\
\hline $\begin{array}{l}\text { C hydroxide used in the } \\
\text { synthesis }\end{array}$ & $\mathrm{NaOH}$ & $\mathrm{NH}_{4} \mathrm{OH}$ \\
\hline
\end{tabular}

Table 2. Matrix of experiments.

\begin{tabular}{cccc}
\hline Sample number & A & B & C \\
\hline 1 & - & - & - \\
\hline 2 & + & - & - \\
\hline 3 & - & + & - \\
\hline 4 & + & + & - \\
\hline 5 & - & - & + \\
\hline 6 & + & - & + \\
\hline 7 & - & + & + \\
\hline 8 & + & + & + \\
\hline
\end{tabular}

After the synthesis, the $\mathrm{pH}$ of the solution was kept alkaline and the product was aged for $96 \mathrm{~h}$ under reflux at the boiling temperature of the mixture in which the glass flask coupled to the condenser was kept under heating using a thermal mantle. After that the gel was vacuum filtered and dried to obtain a powder by freeze-drying. The dry powder was characterized by x-ray diffraction, thermal analysis (thermogravimetric analysis and differential thermal analysis), nitrogen adsorption isotherm, specific surface area by the B.E.T. method and by scanning electron microscopy (SEM) using secondary electron and energy dispersive spectroscopy (EDS) detector.

\subsection{Characterization of the samples}

$\mathrm{X}$-ray diffraction analysis was performed using a Rigaku MultiFlex powder diffractometer with $\mathrm{CuK} \alpha$ radiation $(\lambda=1.542 \AA)$ under operating conditions at $40 \mathrm{KV}$ voltage and $20 \mathrm{~mA}$ current. The scanning angle $(2 \Theta)$ was varied from zero to $90^{\circ}$ at $2^{\circ} \mathrm{min}^{-1}$ scanning speed.

Differential thermal analysis (DTA) and thermogravimetric analysis (TGA) were performed using a Netzsch equipment, model STA 449F3-Jupiter. A quantity of $0.013 \mathrm{~g}$ of sample was placed in open alumina crucible and the DTA-TG measurements were carried out simultaneously. Samples were heated from ambient temperature to $1300^{\circ} \mathrm{C}$ at a rate of $10^{\circ} \mathrm{Cmin}^{-1}$ using a $60 \mathrm{mLmin}^{-1}$ nitrogen flow.

Nitrogen adsorption and desorption isotherms were determined using a Belsorp max equipment. The samples were previously outgassed at $100^{\circ} \mathrm{C}$ for a period of $24 \mathrm{~h}$. The specific surface area was determined by the Brunauer Emmett Teller method ${ }^{16}$ from the nitrogen adsorption isotherms data acquired at $77 \mathrm{~K}$ temperature.

SEM images were obtained using a JEOL JSM-6510 microscope. Samples used for SEM analysis were placed on stubs and coated (using the sputtering technique) with a thin film of gold. Secondary electron detection and an EDS detector were used in our SEM analysis.

\section{Results and Discussion}

\subsection{X-ray diffraction data}

Figure 1 shows the $\mathrm{x}$-ray diffraction patterns of samples 1 to 8 . All samples exhibited the X-ray diffraction peak position characteristic of pseudoboehmite, with a pattern consistent with previous published results ${ }^{17}$. The boehmite phase presents enlarged peaks showing that they have very low average crystallite size and it is difficult to differentiate this phase from pseudoboehmite, beta boehmite and alpha boehmite. So, it was adopted in a generic way as boehmite ICDD 83-2384. The diffraction patterns of samples 2, 4, and 7 exhibited another phase besides pseudoboehmite at $2 \theta \sim 20^{\circ}$ and $2 \theta \sim 40^{\circ}$. This second phase is attributed to bayerite (ICDD 77-117). However, the intensity of the second phase diffraction peaks are smaller than that of pseudoboehmite mainly in samples 2 and 4 . The peaks of bayerite were marked as by in Figure 1. 


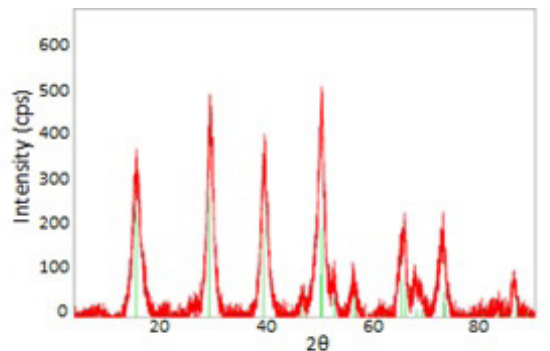

(a)

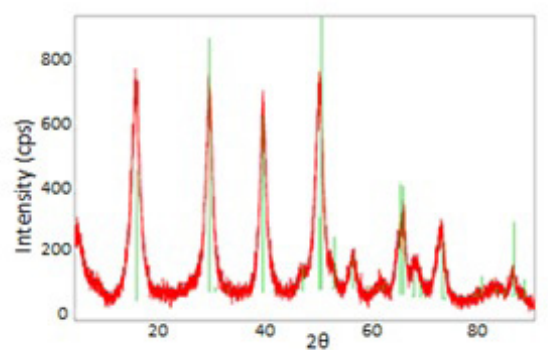

(c)

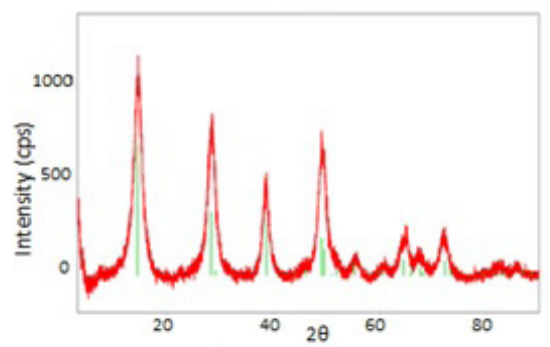

(e)

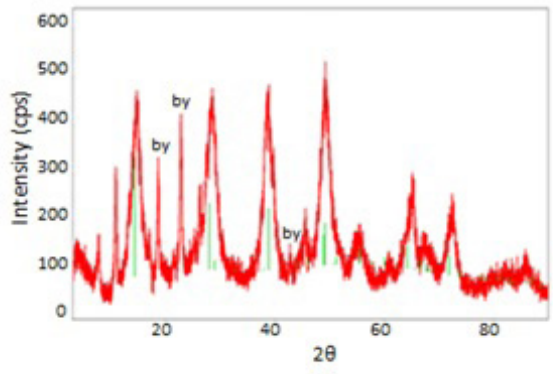

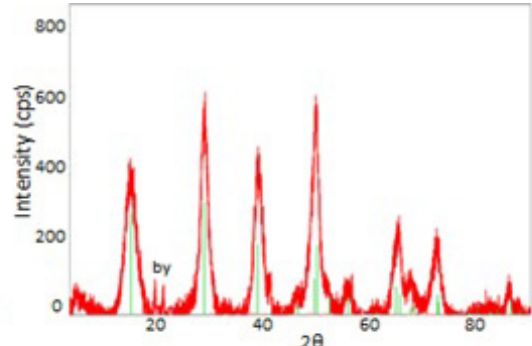

(b)

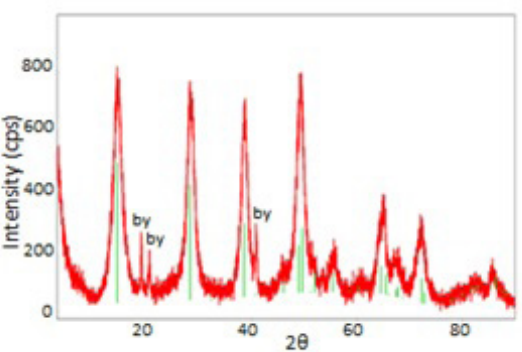

(d)
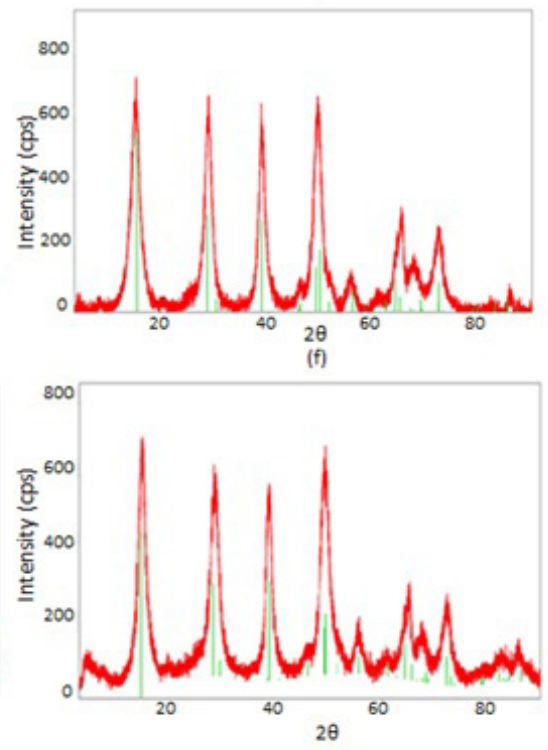

(h)

Figure 1. X-ray diffraction data of samples (sample 1 (a), sample 2 (b), sample 3 (c), sample 4 (d), sample 5 (e), sample 6 (f), sample 7 (g), sample 8 (h). by = peaks attributed to bayerite.

\subsection{Differential thermal analysis and thermogravimetric analysis}

The results of the thermal analysis of sample 1 are presented in Figure 2 where one can observe the standard peaks associated with the pseudoboehmite ${ }^{18,19}$.

An endothermic peak at $\sim 105.4{ }^{\circ} \mathrm{C}$ in DTA was observed and it corresponds to the loss of adsorbed water; the endothermic peak at $\sim 434.1{ }^{\circ} \mathrm{C}$ (observed in the second derivative thermogravimetry, $2^{\text {nd }}$ peak DTG), corresponds to the transformation of the pseudoboehmite into $\gamma-\mathrm{Al}_{2} \mathrm{O}_{3}$. The exothermic peak at DTA for the final transformation into $\alpha-\mathrm{Al}_{2} \mathrm{O}_{3}$, the most stable alumina phase, occurs at $\sim 1220.5^{\circ} \mathrm{C}$. We determined a mass loss of $21.71 \mathrm{wt} \%$, from room temperature to $1300{ }^{\circ} \mathrm{C}$.

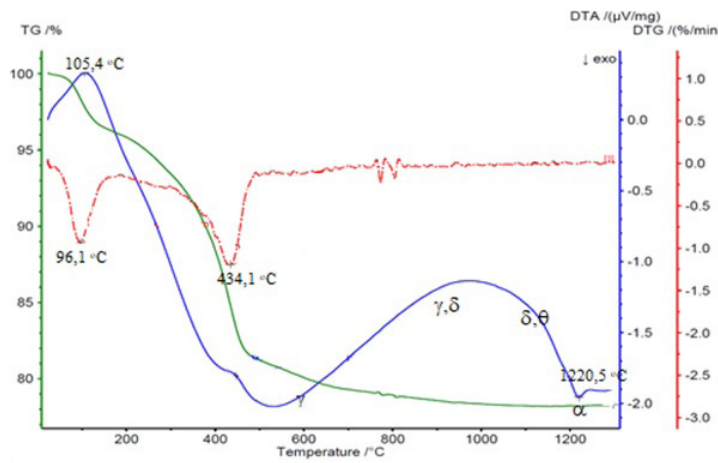

Figure 2. DTA and TG analysis of sample 1. 
Table 3 shows the results from the DTA and TG analysis. The analyzed data was: the peak of the1st DTG (associated with the loss of water), $2^{\text {nd }}$ peak DTG (associated with the transformation of pseudoboehmite into $\gamma-\mathrm{Al}_{2} \mathrm{O}_{3}$ ) and last peak in DTA (temperature of $\alpha-\mathrm{Al}_{2} \mathrm{O}_{3}$ formation). The other phases transformation $(\gamma, \delta, \theta)$ were not observed at DTA. The probable temperature of formation of the other phases according to the literature ${ }^{20}$ is shown in Figure 2.

The results listed in Table 3 were treated using the $2^{3}$ factorial experimental design and the results are presented in Table 4.

In the $1^{\text {st }}$ peak DTG results the interactive effects were, in increasing order, $\mathrm{AC}$ and $\mathrm{AB}$. In the $2^{\text {nd }}$ peak DTG the main effect observed was the alkali font. According to factorial experimental design results when the $\mathrm{NaOH}$ was changed to $\mathrm{NH}_{4} \mathrm{OH}$, there was a reduction in the temperature of the pseudoboehmite due to the $\gamma-\mathrm{Al}_{2} \mathrm{O}_{3}$ transformation. It was also observed that interactive effects were significant, in increasing order, $\mathrm{AB}, \mathrm{BC}$ and $\mathrm{AC}$. Considering that variable $\mathrm{B}$ is related to acetate ions, the interaction of this ions with the aluminum precursor salt and the hydroxide used has a significant influence on pseudoboehmite synthesis. Thus, as the acetate ion appears in two interactions, it can be stated that this variable is the most important in the synthesis of pseudoboehmite.

In the temperature of $\alpha-\mathrm{Al}_{2} \mathrm{O}_{3}$ formation the interactive effects were also more important than the main effects. The interactive effect with more significance was the AB, which is related to the aluminum precursor and acetate addition.

Considering that the interaction $\mathrm{AB}$ was relevant in the 3 results, for the studied synthesis, the aluminum precursor and the acetate addition interaction increase the temperature of the $1^{\text {st }}$ and $2^{\text {nd }}$ peaks of DTG and promoted the reduction of the $\alpha-\mathrm{Al}_{2} \mathrm{O}_{3}$ formation.

\subsection{Nitrogen isotherms and specific surface area}

The specific surface area data are presented in Table 5. The values of the specific surface area are very high when compared to the data reported in the literature ${ }^{9,21}$. There is no significant difference in the specific surface area among the investigated samples. The crystallite size of boehmite and pseudoboehmite, and the specific surface area, has a strong correlation with the formation temperature of $\gamma-\mathrm{Al}_{2} \mathrm{O}_{3}$ and the phase transition temperature of $\theta$ - to $\alpha-\mathrm{Al}_{2} \mathrm{O}_{3}{ }^{9,18}$. But comparing previous results ${ }^{9,18}$ with the listed data in Table 5, the differences of the values in Table 5 were so small that that they promote no change in the temperature of the pseudoboehmite to $\gamma-\mathrm{Al}_{2} \mathrm{O}_{3}$ and the $\theta$ - to $\alpha-\mathrm{Al}_{2} \mathrm{O}_{3}$ phase transformation. The phase transformation diminishes the value of specific surface area with the increase of temperature. In literature the only exception is the carbon coated alumina that hinders the sintering of the $\delta-\mathrm{Al}_{2} \mathrm{O}_{3}^{22,23}$.

According to the data and taking the calculations for factorial planning $2^{3}$ we determined the corresponding specific surface area results which are listed in Table 6. Note that the variables $A$ and $C$, individually, are not significant in relation to the specific area, but again the interactions are significant for the specific surface area results. In the specific surface area, the interactive effects were, in increasing order, $\mathrm{AB}$, $\mathrm{BC}$ and $\mathrm{AC}$. This result is the same for the $2^{\text {nd }}$ peak DTG. As observed in the thermal analysis results the aluminum precursor and the acetate addition interaction are significant for the specific surface area results.

$\mathrm{N}_{2}$ adsorption-desorption isotherms of the samples show that they correspond to type IV of the International Union of Pure and Applied Chemistry (IUPAC) classification ${ }^{24}$, which indicates that the pores of the samples are composed of mesopores and macropores. Figure 3 shows the adsorption and desorption isotherms obtained for all samples.

Table 3. DTA and TG results.

\begin{tabular}{|c|c|c|c|}
\hline Sample & $1^{\text {st }}$ peak of the DTG & $2^{\text {nd }}$ peak of DTG & $\begin{array}{c}\text { Temperature }\left({ }^{\circ} \mathrm{C}\right) \text { of } \alpha-\mathrm{Al}_{2} \mathrm{O}_{3} \\
\text { formation in DTA }\end{array}$ \\
\hline 1 & 96.1 & 434.1 & 1220.5 \\
\hline 2 & 84.9 & 438.8 & 1267.4 \\
\hline 3 & 101.1 & 421.9 & 1284.6 \\
\hline 4 & 95.7 & 418.6 & 1260.2 \\
\hline 5 & 93.2 & 413.3 & 1256.0 \\
\hline 6 & 85.0 & 324.4 & 1292.5 \\
\hline 7 & 90.9 & 399.7 & 1293.0 \\
\hline 8 & 103.4 & 395.3 & 1235.3 \\
\hline
\end{tabular}

Table 4. Factorial $2^{3}$ experimental design results for the $1^{\text {st }}$ and 2 nd DTG peaks and the temperature of $\alpha-\mathrm{Al}_{2} \mathrm{O}_{3}$ formation.

\begin{tabular}{lcrr}
\hline Medium effects and interactions & $1^{\text {st }}$ peak DTG & $2^{\text {nd }}$ peak DTG & $\alpha-\mathrm{Al}_{2} \mathrm{O}_{3}$ formation \\
\hline Medium & 93.8 & 405.8 & 1263.7 \\
\hline Main effect & & & 0.3 \\
\hline A & -3.1 & -23.0 & 9.2 \\
\hline B & 8.0 & 6.2 & 11.0 \\
\hline C & -1.3 & -45.2 & -41.4 \\
\hline Interactions between factors & & & -10.9 \\
\hline AB & 6.6 & 19.1 & -19.3 \\
\hline AC & 5.2 & -23.7 & -5.7 \\
\hline BC & 0.1 & 22.4 & \\
\hline ABC & 3.7 & 23.1 & \\
\hline
\end{tabular}


The hysteresis loops may exhibit a wide variety of shapes, and according to Sing et al. ${ }^{24}$, they provide the information about the material structure. Adsorption hysteresis arises when the adsorption and desorption of nitrogen curves do not coincide. The hysteresis appearing in the multilayer range of physisorption isotherms is associated with capillary condensation in mesopore materials.

Sample 2 has a hysteresis type H3. According to the literature ${ }^{24}$ the Type H3 loop does not exhibit any limiting adsorption at high $\mathrm{p} / \mathrm{p}^{\circ}$. It is observed in aggregates of primary particles that have a lamellar habit, plate-like particles, and indicate the adsorption of nitrogen in the slit-shaped pores. According to Sing et al. ${ }^{24}$, "an agglomerate is defined as an assemblage of particles rigidly joined together and an aggregate as an assemblage of particles which are loosely coherent".

Samples 1,3,4,6 and 7 have a hysteresis with $\mathrm{H} 1$ shape. Type $\mathrm{H} 1$ hysteresis is often associated with porous materials known, from other evidence, to consist of agglomerates or compacts of approximately uniform spheres in regular array.

Table 5. Specific surface area of the samples.

\begin{tabular}{cc}
\hline Sample & Specific surface area $\left(\mathrm{m}^{2} / \mathrm{g}\right)$ \\
\hline 1 & 304.68 \\
\hline 2 & 331.26 \\
\hline 3 & 311.51 \\
\hline 4 & 299.28 \\
\hline 5 & 321.99 \\
\hline 6 & 292.33 \\
\hline 7 & 343.36 \\
\hline 8 & 314.98 \\
\hline
\end{tabular}

Table 6. Full factorial experimental design results for specific surface area.

\begin{tabular}{lc}
\hline Medium effects and interactions & Specific surface area \\
\hline Medium & 314.9 \\
\hline Main effect & \\
\hline $\mathrm{A}$ & -10.9 \\
\hline $\mathrm{B}$ & 4.7 \\
\hline $\mathrm{C}$ & 6.5 \\
\hline Interactions between factors & \\
\hline $\mathrm{AB}$ & -9.4 \\
\hline $\mathrm{AC}$ & -18.1 \\
\hline $\mathrm{BC}$ & 17.3 \\
\hline $\mathrm{ABC}$ & 10.0 \\
\hline
\end{tabular}

The materials with $\mathrm{H} 1$ hysteresis have narrow distributions of pore size. In the literature, there are reports of pseudoboehmite in the plate forms and fibrils. The spheres are not reported. Thus, the samples 1,3,4,6, 7 consist of agglomerates of primary particles.

And finally, samples 5 and 8 have a shape H2. In type $\mathrm{H} 2$ loops, the distribution of pore size and shape is not well defined. Thus, the $\mathrm{H} 2$ loop is especially difficult to interpret and could be associated with the presence of pores with narrow necks and wide bodies. The hysteresis observed for these two samples is an indication of the existence of capillary condensation in mesopores.

\subsection{Scanning electron microscopy}

In the scanning electron micrographs of all samples it is observed that the material presents high porosity. Figure 4 shows the micrographs of all samples obtained using the secondary electron detector.

The SEM image of sample 2 has aggregates as observed in the nitrogen adsorption isotherm. Samples 5 and 8 comprise surfaces with different textures when compared to the other samples. It looks like a less porous surface.

SEM images of samples $1,3,4,6$, and 7 , which have a hysteresis type $\mathrm{H} 1$, revealed that these samples consist of agglomerates of small particles.

SEM analysis using the EDS detector shows that the spectra obtained for $1,2,3,4,5$ and 8 are similar. Figure 5 shows a representative SEM-EDS result for sample 1. The semi-quantitative analysis of the elements revealed that there is an atomic ratio of 1.7 , approximately two oxygen atoms to an aluminum atom. The result for sample 6 is also coherent. Considering that the EDS analysis is semi quantitative, it is difficult to draw conclusions from the results. However, it can be stated that the $\mathrm{O} / \mathrm{Al}$ ratio (Table 7) is within the expected for pseudoboehmite. The EDS of sample 7 shows a bigger atomic ratio (2.1 oxygen atoms to one aluminum atom). Sample 7 contains bayerite and it was observed an increase in the Oxigen/Aluminum ratio. Considering the bayerite chemical formula, $\mathrm{Al}(\mathrm{OH})_{3}$, the increase in $\mathrm{O} / \mathrm{Al}$ ratio for this sample is coherent. It is worth noting that only one sample detected sodium (Table 7, sample 2). Considering that this ion is not beneficial in nanopowders the result is very positive.

Observing Tables 3, 4 and 7, we observe that the small amount of chlorine and sodium did not influence the results of specific surface area and the temperatures of phase transformations of alumina.

Table 7. Full factorial experimental design results for EDS analysis.

\begin{tabular}{|c|c|c|c|c|c|c|}
\hline \multirow{2}{*}{ Sample } & \multicolumn{5}{|c|}{ Atom $\%$} & \multirow{2}{*}{$\mathrm{O} / \mathrm{Al}$ ratio } \\
\hline & Oxygen & Sodium & Aluminum & Silicon & Chlorine & \\
\hline 1 & 61.98 & & 36.65 & 0.91 & 0.47 & 1.7 \\
\hline 2 & 58.10 & 0.68 & 35.51 & 5.71 & & 1.6 \\
\hline 3 & 59.25 & & 37.89 & 1.86 & 1.00 & 1.6 \\
\hline 4 & 61.31 & & 36.94 & 1.75 & & 1.7 \\
\hline 5 & 58.16 & & 38.95 & 1.35 & 1.54 & 1.5 \\
\hline 6 & 65.97 & & 34.03 & & & 2.0 \\
\hline 7 & 63,80 & & 30,80 & 2.80 & 2.60 & 2.1 \\
\hline 8 & 61.45 & & 37.62 & 0.93 & & 1.6 \\
\hline
\end{tabular}




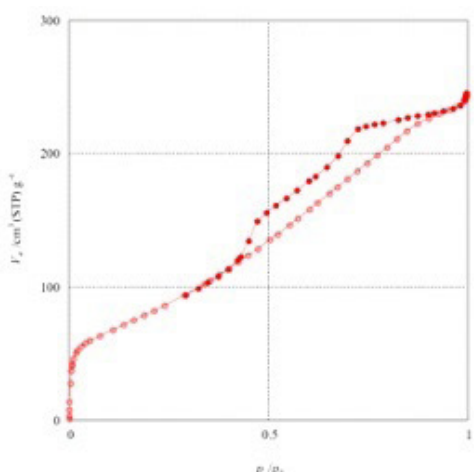

(A)

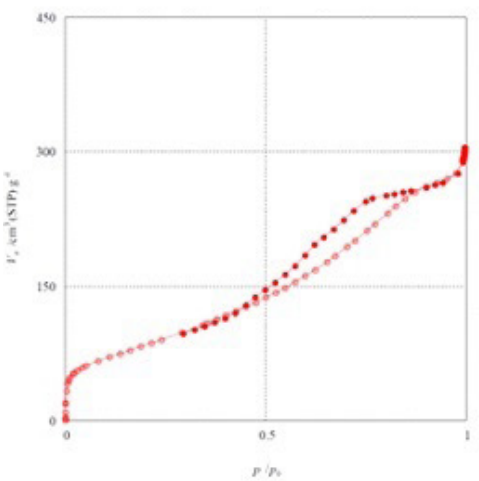

(c)

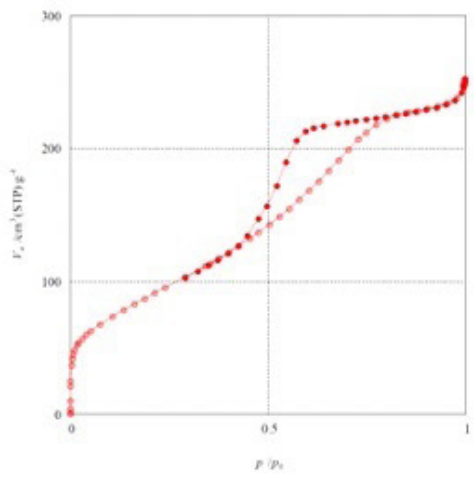

(E)

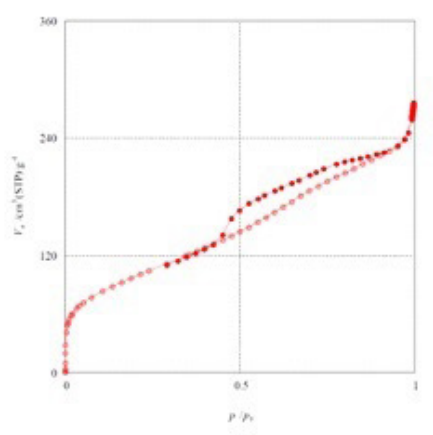

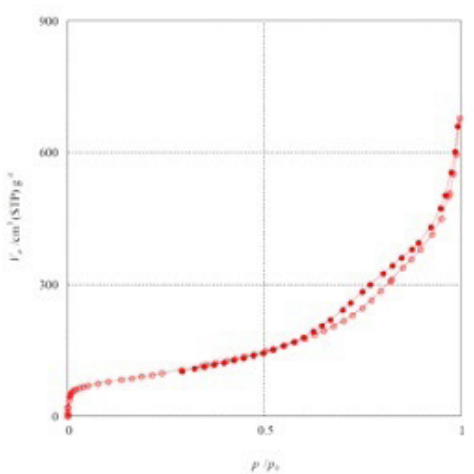

(B)

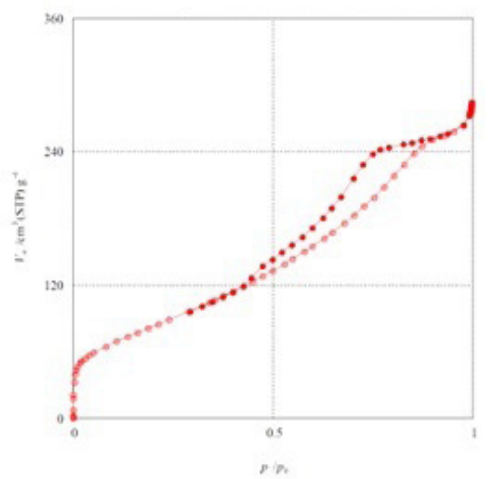

(D)

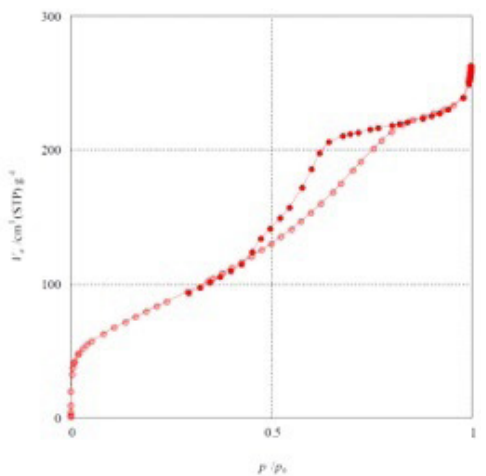

(F)

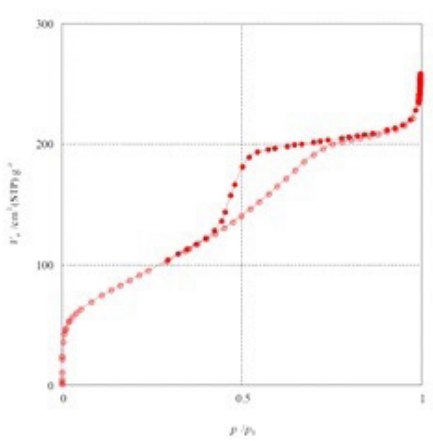

Figure 3. Absorption and desorption isotherms obtained (sample 1 (A), sample 2 (B), sample 3 (C), sample 4 (D), sample 5 (E), sample 6 (F), sample $7(\mathrm{G})$, sample $8(\mathrm{H}))$. 


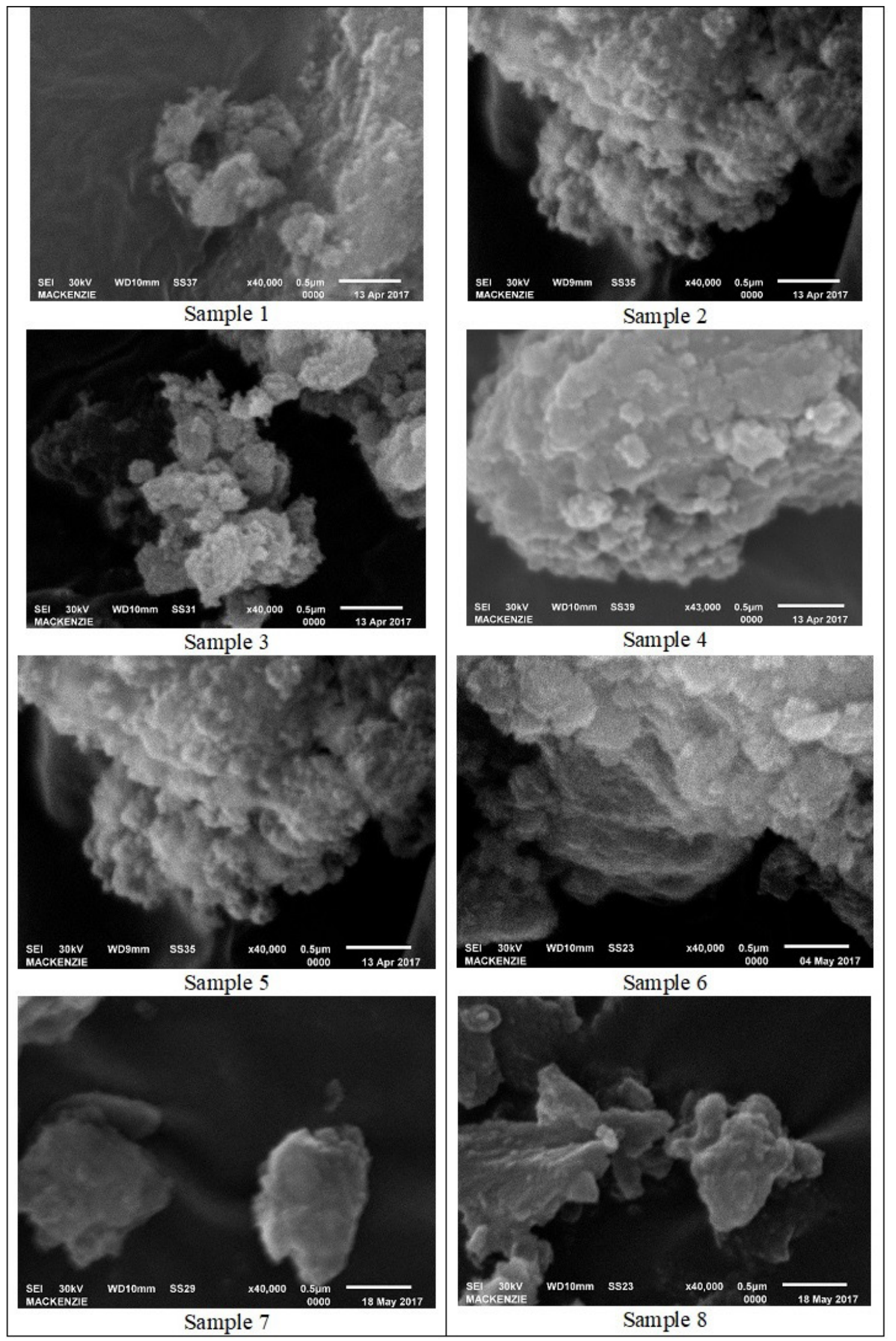

Figure 4. SEM of the samples 1 to 8. 


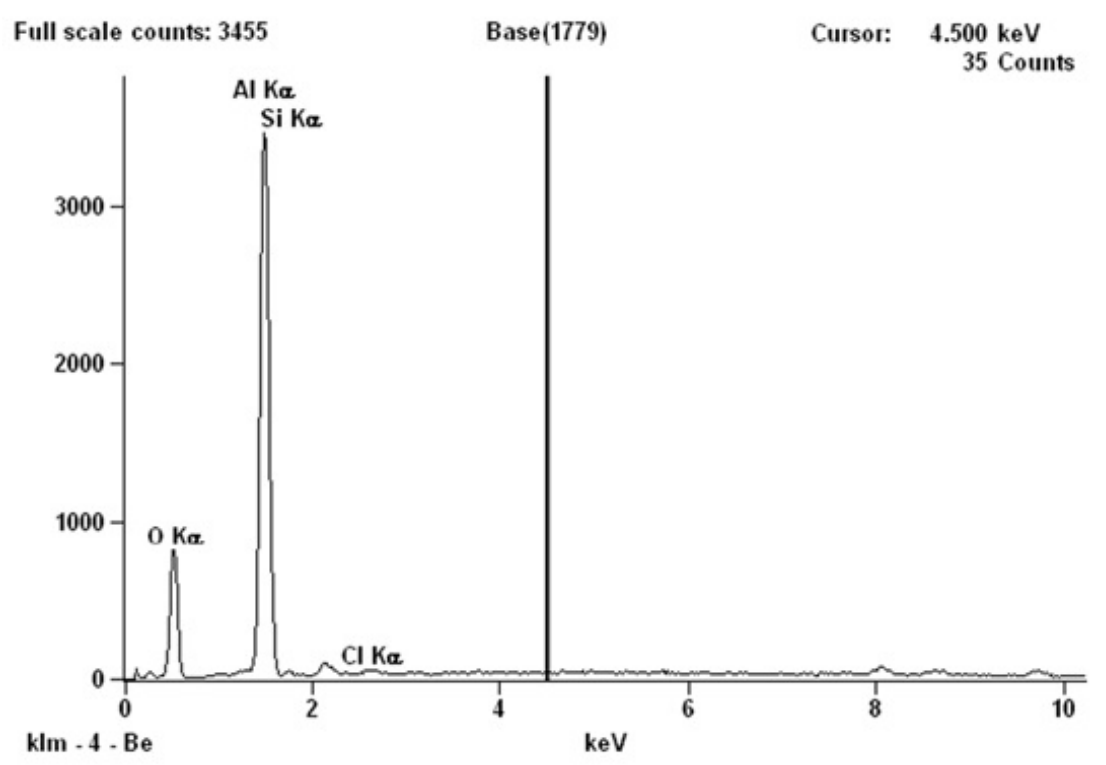

Figure 5. EDS spectrum of sample 1.

\section{Conclusions}

The pseudoboehmite was obtained by precipitating a solution of aluminum salts (aluminum nitrate and aluminum chloride) in the presence of acetate ions (ammonium acetate and sodium acetate) in a basic solution (sodium hydroxide or ammonium hydroxide). In eight different synthesis conditions pseudoboehmite was obtained, confirmed by x-ray diffraction experiments and EDS analysis.

For the conditions and reagents studied it was observed that the use of acetate ion in the synthesis of pseudoboehmite has no influence alone in the temperature of phase transformations and in the specific surface area of the product. The interaction of the acetate with the aluminum precursor and the hydroxide used in the synthesis has a significant effect in the properties of the synthesized product.

The analysis of the DTA and TG data using the $2^{3}$ factorial experimental design shows that the interactions between the studied variables are more important in the temperature of pseudoboehmite to alumina transformations than the main effects. The interaction of aluminum precursor and acetate addition was relevant in the temperatures of phase transformation of pseudoboehmite to alumina. This interaction increases the temperature of the 1 st and 2 nd peaks of DTG and promoted the reduction of the $\alpha-\mathrm{Al}_{2} \mathrm{O}_{3}$ formation.

Using the $2^{3}$ factorial experimental design for the analysis of the specific surface area it was observed also that the interactions are more important than the main effects. For the alumina phase transformations observed in thermal analysis the variable associated with ion acetate appears in two interactions of the $2^{3}$ factorial experimental design.

The analysis of the 8 different samples using nitrogen adsorption isotherm and scanning electron microscopy using secondary electron detector shows that all samples has high porosity and contain mesopores and macropores. The nitrogen adsorption/desorption isotherm indicates that one sample contain aggregates of plate like particles.

\section{Acknowledgments}

The authors thank the Mackenzie Presbyterian University, Texas Tech University, Mack Pesquisa, CAPES, Cnpq and FAPESP (grant 2010/19157-9 and grant 2017/22396-4) for the sponsorship of this project.

\section{References}

1. Moroz EM, Moroz EM, Shefer KI, Shefer KI, Zyuzin DA, Zyuzin DA, et al. Local structure of pseudoboehmites. React Kinet Catal Lett. 2006;87(2):367-75.

2. Kloprogge JT, Duong LV, Wood BJ, Frost RL. XPS study of the major minerals in bauxite: gibbsite, bayerite and (pseudo) boehmite. J Colloid Interface Sci. 2006;296(2):572-6.

3. Park Y, Kim YC, Kim J, Park YK, Choi YS, Kim JM, et al. Ring enlargement of methylcyclopentane over Pt/(HZSM48+pseudoboehmite) catalysts. Catalysts. 2019;9(6):531.

4. Munhoz AH Jr, Romero M Fo, Kleist HA, Moreno GD, Oliveira MO, Peres RM, et al. Synthesis of pseudoboehmite-graphene oxide for drug delivery system. Mater Today Proc. 2019;14:7007.

5. Chen Y, Ai K, Liu Y, Lu L. Tailor-made charge-conversional nanocomposite for $\mathrm{pH}$-responsive drug delivery and cell imaging. Appl Mater Interfaces. 2014;6(1):655-63. http:// dx.doi.org/10.1021/am404761h.

6. Miranda LF, Goulart LJP, Silva LGA, Donadon AC, Yamasaki FY, Munhoz AH Jr. Characterization of polystyrene nanocomposites containing nanoparticles of pseudoboehmite obtained by sol-gel process. J Nano Res. 2017;47:96-105.

7. Özdilek C, Kazimierczak K, van der Beek D, Picken SJ. Preparation and properties of polyamide-6-boehmite nanocomposites. Polymer. 2004;45(15):5207-14.

8. Santos PS, Faria FP, Santos HS. Spatial arrangement of fibrils in concentrated aqueous sols of fibrilar pseudoboehmite. Mater Chem Phys. 2002;76(3):267-73.

9. Guzman-Castillo ML, Bokhimi X, Toledo-Antonio A, SalmonesBlásquez J, Hernández-Beltran F. Effect of boehmite crystallite size and steaming on alumina properties. J Phys Chem. 2001;105(11):2099-106. 
10. Kiyohara PK, Santos HS, Coelho ACV, Santos PS. Structure, surface area and morphology of aluminas from thermal decomposition of $\mathrm{Al}(\mathrm{OH}) \mathrm{CH} 3 \mathrm{COO} 2$ crystals. An Acad Bras Cienc. 2000;72(4):471-95.

11. Denigres RWN Fo, Rocha GA, Montes CR, Coelho ACV. Synthesis and characterization of boehmites obtained from gibbsite in presence of different environments. Mater Res. 2016;19(3):659-68. http://dx.doi.org/10.1590/1980-5373MR-2016-0019.

12. Santos HS, Santos PS. Pseudomorphic formation of aluminas from fibrillar pseudoboehmite. Mater Lett. 1992;13(4-5):175-9.

13. Tregubenko VY, Udras IE, Drozdov VA, Belyi AS. Effect of pseudoboehmite peptization by organic acids on texture characteristics of obtained aluminium oxides. Russ J Appl Chem. 2011;84(1):9-16.

14. Box GEP, Hunter JS, Hunter WG. Statistics for experimenters: an introduction to design data analysis and model building. New York: Wiley Interscience; 1978.

15. Lundstedt T, Seifert E, Abramo L, Thelin B, Nystrom A, Pettersen $\mathrm{J}$, et al. Experimental design and optimization. Chemom Intell Lab Syst. 1998;42(1-2):3-40.

16. Brunauer S, Emmett PH, Teller E. Adsorption of gases in multimolecular layers. J Am Chem Soc. 1938;60(2):309-19.

17. Cai W, Yu J, Cheng B, Su BL, Jaroniec M. Synthesis of boehmite hollow core/shell and hollow microsphere via sodium tartrate-mediated phase transformation and their enhanced adsorption performance in water treatment. J Phys Chem C. 2009;113(33):14739-46.

18. Munhoz AH Jr, Martins MV, Ussui V, Cruz K, Zandonadi AR, Miranda LF. The influence of ageing in pseudoboehmites synthesis. Mater Sci Forum. 2012;727:1795-801.

19. Lu G, Zhang T, Feng W, Zhang W, Wang Y, Zhang Z, et al. Preparation and properties of pseudo-boehmite obtained from high-alumina fly ash by a Sintering-CO2 decomposition process. J Miner Met Mater Soc. 2019;71(2):499-507.

20. Tsuchida T, Ichikawa N. Mechanochemical phenomena of gibbsite, bayerite and boehmite by grinding. Reactivity of Solids. 1989;7(3):207-17.

21. Tsukada T, Segawa H, Yasumori A, Okada K. Crystallinity of boehmite and its effect on the phase transition temperature of alumina. J Mater Chem. 1999;9(2):549-53.

22. Volodin AM, Bedilo AF, Stoyanovskii VO, Zaikovskii VI, Kenzhin RM, Mishakov IV, et al. Nanocrystalline carbon coated alumina with enhanced phase stability at high temperatures. RSC Adv. 2017;7(86):54852-60.

23. Yakovlev IV, Volodin AM, Zaikovskii VI, Stoyanovskii VO, Lapina OB, Vedyagin AA. Stabilizing effect of the carbon shell on phase transformation of the nanocrystalline alumina particles. Ceram Int. 2018;44(5):4801-6.

24. Sing KSW, Everett DH, Haul RAW, Moscou L, Pirotti RA, Rouqueról J, et al. Reporting physisorption data for gas/solid systems with special reference to the determination of surface area and porosity. Pure Appl Chem. 1985;57(4):603-19. 